\title{
Clinical trial on the effects of a free-access acidified milk replacer feeding program on the health and growth of dairy replacement heifers and veal calves
}

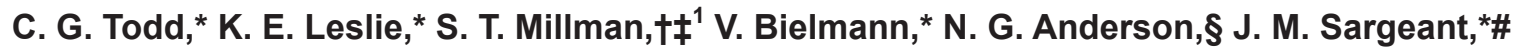 \\ and T. J. DeVriesll \\ *Department of Population Medicine, Ontario Veterinary College, University of Guelph, Guelph, Ontario, Canada, N1G 2W1 \\ †Veterinary Diagnostic and Production Animal Medicine, and \\ ‡Biomedical Sciences, lowa State University, Ames 50011 \\ §Ontario Ministry of Agriculture, Food and Rural Affairs, Veterinary Science and Policy Unit, Elora, Ontario, Canada, NOB 1S0 \\ \#Centre for Public Health and Zoonoses, and \\ IIDepartment of Animal Biosciences, University of Guelph, Guelph, Ontario, Canada, N1G 2W1
}

\begin{abstract}
The objectives of this study were to evaluate the effects of free-access acidified milk replacer feeding on the pre- and postweaning health of dairy and veal calves. Individually housed calves were systematically assigned at birth to 1 of 2 feeding programs: free-access feeding (ad libitum) of acidified milk replacer (ACD, n $=249)$ or traditional restricted feeding $(3 \mathrm{~L}$ fed twice daily) of milk replacer (RES, $\mathrm{n}=249$ ). Calves were fed milk replacer containing $24 \%$ crude protein and $18 \%$ fat. Acidified milk replacer was prepared to a target $\mathrm{pH}$ between 4.0 and 4.5 using formic acid. Calves were weaned off milk replacer at approximately $6 \mathrm{wk}$ of age. Weaning occurred over $5 \mathrm{~d}$, and during this weaning period, ACD calves had access to milk replacer for 12 $\mathrm{h} / \mathrm{d}$ and RES calves were offered only one feeding of milk replacer $(3 \mathrm{~L})$ daily. Calves were monitored daily for signs of disease. Fecal consistency scores were assigned each week from birth until weaning. A subset of calves was systematically selected for fecal sampling at 3 time points between 7 and $27 \mathrm{~d}$ of age. Fecal samples were analyzed for enterotoxigenic Escherichia coli F5, Cryptosporidium parvum, rotavirus, and coronavirus. Hip width, hip height, body length, heart girth, and body weight were measured at birth and weaning. Postweaning body weight measurements were collected from the heifers at approximately 8 mo of age. Postweaning body weight and carcass grading information was collected from the veal calves at slaughter once a live weight between 300 and $350 \mathrm{~kg}$ had been achieved. The odds of ACD calves being treated for a preweaning disease event tended to be lower than that of the RES
\end{abstract}

Received May 4, 2016.

Accepted September 17, 2016.

${ }^{1}$ Corresponding author: smillman@iastate.edu calves (1.2 vs. $5.2 \%$, respectively). Preweaning mortality, postweaning disease treatment, and postweaning mortality did not differ between feeding treatments. The ACD feeding treatment supported greater preweaning average daily gain (0.59 vs. $0.43 \mathrm{~kg} / \mathrm{d})$ and structural growth than RES feeding. Postweaning average daily gain and carcass characteristics were similar for ACD and RES calves. These results indicate that free-access acidified milk replacer feeding tended to support improved health, and greater body weight gain and structural growth during the preweaning period; these effects did not persist in the postweaning period. The growth advantage observed before weaning in the ACD calves likely disappeared due to the weaning methods used.

Key words: acidified milk, free-access milk feeding, growth, health, calf

\section{INTRODUCTION}

Calves on North American dairy and veal farms are generally reared on either a traditional or an enhanced milk feeding program (Drackley, 2008; Khan et al., 2011a). Traditional feeding programs restrict daily intake of fluid milk to a rate of 8 to $10 \%$ of birth BW, with the aim of encouraging solid feed consumption and facilitating earlier weaning (Drackley, 2008). In contrast, enhanced milk feeding strategies allow calves to consume larger quantities of whole milk or high protein milk replacer, which better reflect natural feeding conditions, result in fewer behavioral signs of hunger (De Paula Vieira et al., 2008; Khan et al., 2011a), and support improved growth performance (Diaz et al., 2001; Jasper and Weary, 2002; Quigley et al., 2006; Khan et al., 2007a; Miller-Cushon et al., 2013). Moreover, it has been documented that increased nutrient intake from milk or milk replacer during the preweaning period and 
greater preweaning ADG are positively associated with lactation milk yield (Soberon et al., 2012; Soberon and Van Amburgh, 2013).

Anecdotal reports indicate that free-access acidified milk feeding is an enhanced nutritional program that has been adopted by many dairy and veal calf producers in Canada (Anderson, 2008, 2011). In addition, it has recently been reported that acidified milk is fed to calves on $1.7 \%$ of farms in the United States (NAHMS, 2016). This feeding system aims to achieve ad libitum consumption by using an organic acid to preserve milk so that it can be fed to calves at ambient temperatures in the summer, and at approximately 20 to $24^{\circ} \mathrm{C}$ in cold housing. Several commercial acidified milk replacers have been developed and evaluated for ad libitum feeding, with a typical target $\mathrm{pH}$ between 5.0 and 5.5 after reconstitution (Stobo, 1983; Davis and Drackley, 1998). It has been demonstrated that these commercial acidified milk replacers are associated with improved DMI and greater ADG when offered to calves ad libitum, as compared with traditional feeding (Nocek and Braund, 1986; Woodford et al., 1987). Nocek and Braund (1986) reported that calves fed ad libitum commercial acidified milk replacer had softer manure, likely as a result of consuming a greater proportion of their daily DMI from milk replacer. However, these calves also had a lower incidence of neonatal calf diarrhea complex and required less veterinary care than traditionally fed calves. More recently, a recommended target $\mathrm{pH}$ range between 4.0 and 4.5 for the preparation of acidified milk has been proposed (Anderson, 2008, 2011). Further research, under field conditions, is needed to determine health and performance effects of feeding acidified milk at this lower recommended target $\mathrm{pH}$.

The primary objective of this study was to evaluate the effects of free-access acidified milk replacer feeding on the pre- and postweaning health of dairy and veal calves, under field conditions. The secondary objective was to assess the effects of free-access acidified milk replacer feeding on the preweaning and postweaning growth of dairy and veal calves, and on veal carcass quality. It was hypothesized that calves reared on a free-access acidified milk replacer program would experience fewer disease events, have a lower mortality risk, and show improved BW gain, structural growth, and carcass characteristics when compared with restrictedfed calves.

\section{MATERIALS AND METHODS}

\section{Animals, Housing, and Management}

The University of Guelph Animal Care Committee reviewed and approved all study procedures. This clini- cal trial was conducted on a commercial dairy farm in Ontario, Canada. The lactating herd included approximately 450 Holstein cows (average 305-d milk $=9,750$ $\mathrm{kg}$; fat $=3.8 \%$; protein $=3.2 \%$ ). All calves born on the farm were retained as replacement heifers or reared as grain-fed veal calves. Every calf that was born between March 21 and December 31, 2008, and survived the first $24 \mathrm{~h}$ of life, was eligible for enrollment in the study.

All calves were separated from their dams at first discovery, moved to individual housing in the calf nursery, and fed colostrum. In the nursery, calves were placed in 1 of 24 individual pens constructed with 2 solid plastic dividers and a front gate. The nursery pens were located on concrete flooring and bedded with wood shavings. Each pen was cleaned of all bedding material and washed after every use. Calves in neighboring pens did not have physical contact with each other. The nursery was ventilated using a negative pressure mechanical system, and in-floor heating was used to maintain the room temperature at approximately $20^{\circ} \mathrm{C}$. According to the standard farm protocol, all calves were handfed colostrum as soon as possible after movement to the calf nursery. Details about colostrum management, including feeding time, source, route of administration, number of feedings, and volume of colostrum fed to each calf were recorded by farm personnel. As per standard farm protocol, on the day of birth, calves were uniquely identified with ear tags, the umbilicus was disinfected with iodine, and calves were injected with vitamins A, $\mathrm{D}$, and E, selenium, and iron.

Newborn calves (both replacement heifers and bulls for veal production) were continuously introduced to the nursery room until a block of 14 animals was assembled. Once the youngest calf in the block spent a minimum of $2 \mathrm{~d}$ in the nursery, calves were comingled on a livestock trailer and transported approximately $0.5 \mathrm{~km}$ to the preweaning barn. Each new block of calves was moved into 1 of 5 rooms in the preweaning barn, with each room consisting of 2 rows of 7 individual elevated stalls. Each calf was assigned to a stall in the room according to exit order from the trailer. Stall-side partitions were fabricated out of spindle-style metal that permitted nose-to-nose contact between neighboring calves. Grated flooring allowed manure and urine to drop to the floor and collect in a shallow gutter below the row of stalls. Rooms were managed in an all-in/all-out manner, such that calves from the same block entered and exited the room together. After each use, rooms were cleaned using a high-pressure washer with disinfectant, followed by approximately 1-wk drying time before the next block of calves entered. Mechanical blender systems consisting of variable speed exhaust fans and dampers were used to ventilate the preweaning rooms. Rooms were maintained at ambient temperature during 
the summer months and heated during the remainder of the year. Rooms were initially kept at $20^{\circ} \mathrm{C}$ as calves first entered the preweaning room, after being moved from the nursery. Throughout the preweaning period, the room temperature was programed to gradually decrease to $10^{\circ} \mathrm{C}$. Propane heaters were used to provide supplemental heat during cold periods.

All calves were subjected to similar management procedures from birth until weaning. A commercial starter ration (18\% CP, 2\% fat, Purina Fastart Calf Startena Calf Starter Complete with Decoquinate, Agribrands Purina, Canada Ltd., Woodstock, ON, Canada) was provided for ad libitum intake. Fresh water was provided by bucket from birth until exit from the preweaning barn. Forage was not offered during the preweaning period. As per farm protocol, heifer calves were dehorned within $3 \mathrm{~d}$ of weaning using an electric cautery iron; bull calves were neither dehorned nor castrated.

Calves were moved out of the preweaning barn approximately $1 \mathrm{wk}$ after being weaned from milk replacer. Heifer calves were transported by livestock trailer approximately $5 \mathrm{~km}$ to the postweaning heifer barn, where they were comingled and housed in large groups (20 to 25 calves/group). Heifers were fed ad libitum starter ration for a minimum of 4 wk after weaning and then transitioned to a grower ration, and ad libitum hay was offered throughout this time period. At approximately 6 mo of age, heifers were switched to a TMR and the grower ration was used as top dress. Bull calves were moved to the veal barn, which was immediately adjacent to the preweaning barn, housed in groups ( $<15$ calves/group), and fed a grain-fed veal diet of ad libitum corn and pellets. Veal calves were sent to the slaughter facility when a live weight between 300 and $350 \mathrm{~kg}$ was reached.

\section{Experimental Design and Treatment Allocation}

This study was designed to evaluate 2 feeding programs for preweaned calves: free-access feeding of acidified milk replacer (ACD) versus traditional restricted feeding (3 L fed twice daily) of milk replacer (RES). Sample size calculations (Intercooled Stata 9.1, College Station, TX) were completed to estimate the number of calves required per treatment to detect meaningful differences in preweaning disease treatment. A final sample size of 500 (250 calves per treatment group) was determined, based on the following assumptions: 10 and $35 \%$ expected incidence of preweaning disease for the free-access acidified and control calves, respectively, power of $80 \%$, confidence level of $95 \%$, and an adjustment for clustering within room (intra-class correlation) of 0.3. Expected disease estimates were based on historical calf health information available from onfarm records.

Each individual pen in the nursery room was numbered and systematically designated at the onset of the study as either an ACD or RES pen. The location sequence was balanced for treatment group. Within each block of 14 calves, 7 were allocated to each feeding treatment. Calves were systematically allocated to the next pen in the location sequence based on birth order. Calves were reared on the assigned feeding treatment while housed in the nursery and preweaning rooms. In the preweaning rooms, calves were housed in separate rows by feeding treatment. The installations for the 2 different feeding programs were clearly visible in each stall; therefore, it was not possible to blind the farm personnel and research technicians to treatment assignment when making calf health decisions or when collecting samples and growth measurements. As such, as much as was possible, quantitative outcome measures were used, as opposed to qualitative assessment outcomes.

The ACD and RES calves were fed a nonmedicated commercial milk replacer (Purina Accel 24-18, 24\% CP, $18 \%$ fat, Agribrands Purina Canada Inc.). Milk replacer powder was reconstituted at $130 \mathrm{~g} / \mathrm{L}$. Acidified milk replacer was prepared by cooling milk replacer to a temperature of less than $20^{\circ} \mathrm{C}$ and then stirring in prediluted formic acid (The Acidified Milk Solution, 9.8\% formic acid, NOD Apiary Products Ltd., Frankford, ON, Canada) until a pH between 4.0 and 4.5 was achieved. A waterproof tester (HI 98127 pHep5, Hanna Instruments, Laval, QC, Canada) was used to measure temperature and $\mathrm{pH}$ of the milk replacer each time acidified milk replacer was prepared. The $\mathrm{pH}$ tester was cleaned and calibrated weekly using a cleaning solution (Hanna HI 7061 Electrode Cleaning Solution, Hanna Instruments, Laval, QC, Canada) and pH buffer solutions, respectively. Formic acid is not currently approved by the Food and Drug Administration for acidifying milk or milk replacer. Citric acid is an alternative acidifying agent that could be used in the United States (Hill et al., 2013).

Calves assigned to the ACD feeding program were able to consume unrestricted acidified milk replacer throughout the preweaning period. The ACD calves in the nursery were fed using a teat and bucket feeding system. An artificial teat (Peach Teat, Skellerup Industries, Christchurch, New Zealand) was fastened to the front gate of each ACD pen; calves had continuous access to their teats. Teats were connected by plastic tubes, fitted with 1 -way valves to $20-\mathrm{L}$ feeding buckets with lids. The nursery room was arranged so that feeding buckets were shared between 2 neighboring ACD 
calves. Feeding buckets were filled with acidified milk replacer daily and replenished as needed. All of the feeding buckets were agitated by hand for at least 10 s twice daily. Feeding buckets, teats, and plastic tubes were cleaned and disinfected each time a block of calves exited the nursery.

In the preweaning rooms, ACD calves were fed by a gravity flow feeding system. Large batches of acidified milk replacer were prepared every $3 \mathrm{~d}$ at minimum. The acidified milk replacer was pumped to a bulk tank for storage. Acidified milk replacer was continuously delivered from the bulk tank to each of the 5 rooms in the preweaning barn by a pipeline. In each room, every ACD calf had an artificial teat that was attached to the front of its stall. Teats were attached to the pipeline by plastic lines with one-way valves. Acidified milk replacer was stored in the bulk tank and fed at ambient temperature. The bulk tank was drained every 2 wk so that the automatic wash system could clean the bulk tank, pipeline, and plastic lines.

Calves assigned to the RES feeding program were fed $3 \mathrm{~L}$ of freshly prepared milk replacer twice daily. At each feeding, milk replacer was mixed and immediately fed to the RES calves. All of the RES calves were fed milk replacer from individual plastic pails while in the nursery and preweaning rooms. Pails were not fitted with an artificial teat, requiring RES calves to drink rather than suck their daily allowance of milk replacer. The RES feeding program was consistent with the feeding approach that had been used for several years on the farm.

The target age for weaning calves off milk was $6 \mathrm{wk}$, with the decision to wean a room of calves influenced by several factors, including space availability, calving patterns, and calf performance. All calves in the same room were weaned on the same day. Thus, there were specific situations where calves were weaned earlier or later than the target age of 6 wk. During the $5 \mathrm{~d}$ preceding weaning, access to acidified milk replacer was restricted to $12 \mathrm{~h} / \mathrm{d}$ for ACD calves, whereas RES calves were offered only the morning feeding of milk replacer (3 L) daily.

\section{Collection of Health Data}

Research technicians visited the study farm every Thursday from March 2008 until February 2009. All calves housed in nursery room and preweaning rooms were assessed by technicians during these visits. Hindquarters, tails, and manure that collected on pen floors were visually inspected during each visit, from which every calf was assigned a weekly fecal consistency score using a standardized calf health scoring system. Fecal consistency was assessed on a 4 -point scale: $0=$ normal, 1 = semi-formed and pasty, $2=$ loose consistency, 3 = watery consistency. Descriptions and photographs for each consistency fecal score were provided to technicians.

Fecal samples were obtained from a subset of calves at weekly farm visits. A systematic approach of alternating pens was used in the selection of calves for fecal sampling. Three grab samples were collected from the rectum of each selected calf at 7 to $13 \mathrm{~d}$ of age, 14 to $20 \mathrm{~d}$ of age, and 21 to $27 \mathrm{~d}$ of age. Fecal samples were labeled, frozen at $-20^{\circ} \mathrm{C}$, and analyzed using Bio-X lateral immuno-chromatography test strips (Tetrastrips BIO K 156, Bio-X Diagnostics, Jemelle, Belgium) for detection of enterotoxigenic Escherichia coli F5, Cryptosporidium parvum, rotavirus, and coronavirus in calf feces (Trotz-Williams et al., 2005). The laboratory technician that performed all of the fecal sample analyses was blind to treatment assignment.

At the weekly farm visits, a single blood sample was collected by jugular venipuncture (BD Vacutainer Blood Collection Tube, $10 \mathrm{~mL}$, without anticoagulant, Becton Dickinson and Company, Franklin Lakes, NJ) from every newly enrolled calf that was greater than 24 $\mathrm{h}$ of age. These blood samples were centrifuged, serum harvested, and analyzed for serum total protein concentration by digital refractometry (Digital Refractometer \#300027, Sper Scientific, Scottsdale, AZ).

Farm personnel were responsible for detection and treatment of all disease events. According to standard farm protocol, calves were monitored daily by personnel for changes in appetite, attitude (general behavior and responsiveness), fecal consistency, hydration, nasal and ocular discharge, and cough using a standardized calf health scoring system (McGuirk, 2008). Rectal temperature was assessed for any calf that presented with clinical signs of disease.

Neonatal calf diarrhea complex was defined by manure of loose consistency for greater than 2 d. Dehydration associated with neonatal calf diarrhea complex was treated according to severity with either oral electrolyte solution or intravenous replacement fluids for $2 \mathrm{~d}$. Calves with neonatal calf diarrhea complex were also treated with systemic antibiotics (Borgal, trimethoprim, and sulfadoxine injectable solution, Merck Animal Health-Intervet Canada Corp., Kirkland, QC, Canada, and Penicillin G, Dominion Veterinary Laboratories Ltd., Winnipeg, MB, Canada), according to the farm protocol.

Respiratory disease was defined by fever (greater than $39.5^{\circ} \mathrm{C}$ ), increased respiratory rate, and at least one other clinical sign of disease, including depression, nasal or ocular discharge, cough, reduced appetite or 
rough hair coat. Calves with respiratory disease were treated with a regimen of systemic antibiotics and corticosteroids (either a combination of Draxxin Injectable Solution, tulathromycin, Pfizer Animal Health, Pfizer Canada Inc., Kirkland, QC, Canada; Nuflor Sterile Injectable Antibiotic Solution, florfenicol, Merck Animal Health-Intervet Canada Corp.; or Bio-Mycin 200, oxytetracycline injection, Boehringer Ingelheim Vetmedica, Burlington, ON, Canada, along with Predef, isoflupredone acetate, Pfizer Animal Health, Pfizer Canada Inc.).

Omphalophlebitis was defined by an enlarged umbilicus or purulent discharge from the umbilical structures. Joint infection was defined by swelling or stiffness of 1 or more of the joints. Calves with omphalophlebitis or joint infection were treated with a regimen of systemic antibiotics (Borgal, trimethoprim, and sulfadoxine injectable solution, Merck Animal Health-Intervet Canada Corp., and Penicillin G, Dominion Veterinary Laboratories Ltd.).

For any calf that died during the study, farm personnel recorded the suspected cause of death. All disease treatments and mortality information were entered into DairyCOMP 305 (Valley Agricultural Software, Tulare, $\mathrm{CA}$ ), and at a later date these data were retrieved from the farm file for the current study.

\section{Collection of Performance Data}

Farm personnel weighed calves with a calibrated livestock scale immediately after removal from the maternity area. All birth BW data were entered into and subsequently retrieved from DairyCOMP 305. A weaning BW measurement was obtained for each calf approximately $1 \mathrm{wk}$ after weaning, when the calf was moved to postweaning housing. Postweaning followup weights were collected for heifer and veal calves at approximately $8 \mathrm{mo}$ of age (range: 7 to $12 \mathrm{mo}$ ) and immediately before leaving the farm for slaughter, respectively.

At each weekly visit, technicians collected hip width and height, body length, and heart girth measurements for every calf born since the previous visit. Hip width was defined as distance between the greater trochanters of the left and right femurs and was measured using a hipometer instrument (Dairy Innovations, Alexander, NY). Hip height was defined as distance from the floor to the tuber coxae (point of hip). Body length was defined as distance on the dorsal midline from withers to tuber ischium (pin bone). Hip height and body length were measured using a livestock teletape (Deluxe Livestock Measure, Ketchum Manufacturing Inc., Brockville, Ontario, Canada). Heart girth was defined as total distance around the thoracic region, immediately caudal to the forelimb of the calf, and was measured using a weigh tape (Coburn Dairy Calf Tape, The Coburn Company Inc., Whitewater, WI). Technicians measured hip width, hip height, body length, and heart girth at first visit after calves were weaned off milk replacer, before being moved to postweaning housing.

Carcass grading information was obtained for a subset of veal calves $(n=90)$. A certified meat grader with the Canadian Food Inspection Agency evaluated carcasses for maturity, muscling, and color characteristics. This individual was blinded to treatment assignment.

\section{Statistical Analysis}

All statistical analyses were performed using SAS 9.2 (SAS Institute Inc., Cary, NC). The main effect of interest for all analyses was milk feeding treatment. Summary statistics and frequency tables were initially generated to compare the treatment groups for calvingrelated factors, colostrum management, and structural characteristics at birth. Student's $t$-tests, Pearson's $\chi^{2}$ test, and Fisher's exact test (expected count of less than 5 in any category) were used to statistically compare treatment groups at baseline. To ensure that ages at weaning, postweaning follow-up, and slaughter were similar by feeding group, Kaplan-Meier survival estimates were generated and log-rank $\chi^{2}$ was used to test for differences by treatment (Dohoo et al., 2009). Calves that died before weaning, postweaning followup, or slaughter were treated as censored observations in these analyses.

Generalized linear mixed models were constructed to examine the effects of milk feeding treatment on the health and growth of the calves (Dohoo et al., 2009). The primary health outcome of interest was preweaning disease treatment. Additional health outcome variables were pre- and postweaning mortality, postweaning disease treatment, fecal consistency, C. parvum shedding, rotavirus shedding, and coronavirus shedding. Growth outcome variables were pre- and postweaning ADG, BW at weaning, hip width growth, hip height growth, body length growth, heart girth growth, BW at postweaning follow-up for heifer calves, and live weight at slaughter for veal calves.

All health outcome variables, except fecal consistency, were treated as categorical data. Pre- and postweaning disease treatment was defined as calves being treated for at least one disease event before and after weaning, respectively. All causes of disease were included in the disease treatment risks. Odds of pre- and postweaning disease treatment, mortality, and fecal pathogen shedding between feeding groups were modeled with 
a binomial distribution and a logit link. Mean fecal consistency was modeled with a normal distribution and an identity link. Models for health outcome variables included random effects to account for block, calf room, and row. Fecal consistency and enteropathogen shedding models also included a repeated measures statement to account for correlation between weekly measurements.

All growth outcome variables were treated as continuous data. Preweaning ADG, hip width growth, hip height growth, body length growth, and heart girth growth were outcome variables that described changes in BW and structural growth between birth and weaning. Postweaning ADG described changes in BW after weaning. In contrast, BW at weaning, BW at postweaning follow-up, and live weight at slaughter were point in time measurements. Growth outcome variables were modeled with a normal distribution and an identity link, and included random effects to account for block, calf room, and row.

Milk feeding treatment was included in all of the models, regardless of significance. Weekly visit was also offered into models for fecal consistency and enteropathogen shedding as a fixed categorical independent variable. Independent effects of feeding treatment and week on fecal consistency and shedding of enteropathogens were assessed. Interaction between treatment and week was tested when overall effects were significant. Tukey adjustment was specified to account for multiple comparisons. All of the final models were evaluated for assumptions of homoscedasticity and normality of residuals. Homoscedasticity was assessed by visually examining a scatter-plot of residuals against predicted values. Normality was assessed using histogram and normal probability plots, as well as checking the residuals for skewness and kurtosis. A square-root transformation was applied to improve homoscedasticity and to help normalize distribution of residuals for the BW at weaning model. Back-transformed means and $95 \%$ confidence intervals are presented. Model fit was examined by identifying the correlation structure that resulted in the smallest Akaike information criterion. A first-order autoregressive correlation structure was specified for $C$. parvum shedding, rotavirus shedding, and coronavirus shedding models.

\section{RESULTS}

A total of 502 live-born Holstein calves were eligible for enrollment. The majority were born during summer and fall months (spring: March, April, and May = 23.9\%; summer: June, July, and August $=32.5 \%$; fall: September, October, and November $=32.1 \%$; winter: December $=11.5 \%)$. One newborn bull calf presented with clinical signs consistent with congenital malformation and was excluded from the study. Systematic assignment to feeding group resulted in $250 \mathrm{ACD}$ calves (117 heifer calves and 133 bull calves) and 251 RES calves (118 heifer calves and 133 bull calves). After enrollment, 1 ACD bull calf was removed from the study because of poor feet and legs. Additionally, 2 RES bull calves were removed from the study; 1 calf developed a severe joint infection and the other calf was reared on the wrong milk feeding treatment while housed in the preweaning barn. All data from these 3 calves were excluded from statistical analyses. Thus, data were available for 249 calves per treatment group.

Summary information about the calves appears in Table 1. Calves from twin births were more frequently assigned to the ACD treatment group. However, twins represented a relatively small proportion $(4.6 \%)$ of the overall study sample. Treatment assignment was not associated with any of the other calving factors, colostrum management, serum total protein concentration, or birth structural measurements. The ACD and RES treatment groups were balanced for number of bull and heifer calves enrolled $(P=0.93)$. Thus, systematic assignment to treatment group resulted in calves being similar at baseline.

Preweaning disease treatment and mortality risks are reported in Table 2. Median age at weaning for ACD and RES calves was 42.0 and $41.0 \mathrm{~d}$, respectively $(P=0.45)$. The odds of ACD calves being treated for a preweaning disease event tended to be lower than that of RES calves [odds ratio (OR), 95\% CI: 0.2, 0.1 to $1.1 ; P=0.07]$. Two ACD calves and 9 RES calves required treatment during the preweaning period for neonatal calf diarrhea complex, and $1 \mathrm{ACD}$ calf and 5 RES calves were treated for omphalophlebitis and respiratory disease, respectively. Calves did not differ by milk feeding treatment for preweaning mortality (OR, $95 \%$ CI: $1.1,0.4$ to $3.2 ; P=0.79)$. Deaths of 4 ACD calves and 5 RES calves were associated with neonatal calf diarrhea complex, and 1 RES calf died of bloat. Causes of death for an additional 3 ACD calves and 2 RES calves were not determined. Average age at death for ACD calves and RES calves was 20.9 and $14.3 \mathrm{~d}$, respectively.

Differences in preweaning growth performance are summarized by milk feeding treatment in Table 2. The ACD calves had greater ADG during the preweaning period and greater BW at weaning relative to RES calves. The ACD feeding treatment also was associated with greater preweaning structural growth for all anatomical measurements.

Effects of milk feeding treatment on fecal consistency and shedding of enteropathogens are presented in Table 3. Calves assigned to the ACD feeding treatment had 
Table 1. Calving factors, colostrum management, serum total protein concentration, and structural characteristics at birth for Holstein calves assigned to free-access acidified (ACD) ${ }^{1}$ and restricted (RES) ${ }^{2}$ milk replacer feeding treatments

\begin{tabular}{|c|c|c|c|}
\hline Outcome & ACD treatment & RES treatment & $P$-value \\
\hline Number of calves, no. & 249 & 249 & \\
\hline Calving location, $\%$ & & & 1.00 \\
\hline Maternity area & 97.9 & 98.3 & \\
\hline Dry cow free-stall & 2.1 & 1.7 & \\
\hline Calving assistance categories, \% & & & 0.78 \\
\hline Unobserved & 73.8 & 74.5 & \\
\hline Observed and required no assistance & 10.4 & 9.1 & \\
\hline Required minimal assistance & 8.3 & 6.9 & \\
\hline Dystocia & 7.5 & 9.5 & \\
\hline Twin calves, \% & 6.8 & 2.4 & 0.02 \\
\hline Timing of first colostrum feeding, $\%$ & & & 0.74 \\
\hline$<2 \mathrm{~h}$ after birth & 75.8 & 77.3 & \\
\hline$\geq 2 \mathrm{~h}$ and $<4 \mathrm{~h}$ after birth & 20.2 & 20.0 & \\
\hline$>4 \mathrm{~h}$ after birth & 4.0 & 2.7 & \\
\hline Colostrum source, \% & & & 0.29 \\
\hline Dam colostrum only & 2.1 & 3.8 & \\
\hline Pooled colostrum & 97.9 & 96.2 & \\
\hline Route of administration, $\%$ & & & 0.87 \\
\hline Nurse bottle & 28.1 & 28.4 & \\
\hline Esophageal feeder & 26.9 & 28.8 & \\
\hline Nurse bottle and then esophageal feeder & 45.0 & 42.8 & \\
\hline Number of colostrum feedings, ${ }^{3}$ no. & $2(1,2)$ & $2(1,2)$ & 0.86 \\
\hline Total volume of colostrum fed, ${ }^{3} \mathrm{~L}$ & $6.0(2.0,9.0)$ & $6.0(2.0,6.0)$ & 0.84 \\
\hline Serum total protein concentration, ${ }^{4,5} \mathrm{~g} / \mathrm{dL}$ & $5.6(4.1,7.8)$ & $5.7(3.8,7.4)$ & 0.57 \\
\hline Birth BW, ${ }^{4,6} \mathrm{~kg}$ & $42.1(24.5,55.3)$ & $42.1(28.1,56.7)$ & 0.99 \\
\hline Birth hip width, ${ }^{4,7} \mathrm{~cm}$ & $20.7(16.0,24.0)$ & $20.8(17.0,25.0)$ & 0.55 \\
\hline Birth hip height, ${ }^{4,7} \mathrm{~cm}$ & $78.2(64.0,90)$ & $78.4(66.0,89.0)$ & 0.53 \\
\hline Birth body length ${ }^{4,7} \mathrm{~cm}$ & $58.6(47.0,71.0)$ & $58.9(51.0,70.0)$ & 0.32 \\
\hline Birth heart girth, ${ }^{4,7} \mathrm{~cm}$ & $78.9(63.5,88.9)$ & $78.9(68.5,87.6)$ & 0.98 \\
\hline
\end{tabular}

${ }^{1}$ Calves assigned to the ACD treatment had free access to milk replacer acidified to a target $\mathrm{pH}$ between 4.0 and 4.5 .

${ }^{2}$ Calves assigned to the RES treatment were fed $3 \mathrm{~L}$ of milk replacer twice daily.

${ }^{3}$ Median (minimum, maximum) are presented.

${ }^{4}$ Mean (minimum, maximum) are presented.

${ }^{5}$ Measured between 1 and $8 \mathrm{~d}$ of age.

${ }^{6}$ Measured at $0 \mathrm{~d}$ of age

${ }^{7}$ Measured between 0 and $7 \mathrm{~d}$ of age.

Table 2. Preweaning disease treatment, mortality, BW gain, and structural growth for Holstein calves assigned to free-access acidified $(\mathrm{ACD})^{1}$ and restricted (RES) ${ }^{2}$ milk replacer feeding treatments

\begin{tabular}{lccc}
\hline Outcome & ACD treatment & RES treatment & $P$-value \\
\hline Number of calves, no. & 249 & 249 & \\
${\text { Preweaning disease treatment, }{ }^{3} \text { no. }(\%)}_{\text {Preweaning mortality, }^{4} \text { no. }(\%)}^{3(1.2)}$ & $7(2.8)$ & $8(5.2)$ & 0.07 \\
Preweaning growth $^{5}$ & & & 0.79 \\
ADG, kg/d & $0.59(0.55,0.62)$ & $0.43(0.39,0.46)$ & $<0.001$ \\
BW at weaning, kg & $69.1(67.0,71.2)$ & $62.6(60.6,64.6)$ & $<0.001$ \\
Hip width growth, cm & $3.6(3.3,4.0)$ & $2.5(2.2,2.8)$ & $<0.001$ \\
Hip height growth, cm & $8.5(7.6,9.3)$ & $6.9(6.1,7.8)$ & $<0.001$ \\
Body length growth, cm & $12.2(10.8,13.6)$ & $9.6(8.2,11.0)$ & $<0.001$ \\
Heart girth growth, cm & $12.9(11.9,13.9)$ & $9.9(8.9,10.9)$ & $<0.001$ \\
\hline
\end{tabular}

${ }^{1}$ Calves assigned to the ACD treatment had free access to milk replacer acidified to a target $\mathrm{pH}$ between 4.0 and 4.5 .

${ }^{2}$ Calves assigned to the RES treatment were fed $3 \mathrm{~L}$ of milk replacer twice daily.

${ }^{3}$ Treated for at least one disease event between birth and weaning.

${ }^{4}$ Died before being weaned off milk.

${ }^{5}$ Least squares means $(95 \% \mathrm{CI})$ are presented. 
Table 3. Fecal consistency and shedding of enteropathogens for Holstein calves assigned to free-access acidified $(\mathrm{ACD})^{1}$ and restricted $(\mathrm{RES})^{2}$ milk replacer feeding treatments

\begin{tabular}{|c|c|c|c|}
\hline Outcome & ACD treatment & RES treatment & $P$-value \\
\hline $\begin{array}{l}\text { Number of calves, }{ }^{3}{ }^{4} \text { no. } \\
\text { Fecal consistency }{ }^{4,5,6}\end{array}$ & 249 & 249 & \\
\hline Wk 1 visit & $1.0(0.8,1.1)$ & $1.0(0.9,1.1)$ & 1.00 \\
\hline Wk 2 visit & $1.5(1.4,1.7)$ & $1.4(1.3,1.5)$ & 0.89 \\
\hline Wk 3 visit & $1.4(1.3,1.5)$ & $1.3(1.2,1.4)$ & 0.95 \\
\hline Wk 4 visit & $1.0(0.9,1.1)$ & $0.8(0.7,0.9)$ & 0.16 \\
\hline Wk 5 visit & $0.8(0.7,0.9)$ & $0.4(0.3,0.5)$ & $<0.001$ \\
\hline Wk 6 visit & $0.5(0.4,0.6)$ & $0.3(0.1,0.4)$ & 0.09 \\
\hline Number of calves sampled, no. & 119 & 120 & \\
\hline Number of fecal samples collected, ${ }^{7}$ no. & 357 & 360 & \\
\hline \multicolumn{4}{|l|}{ Shedding of enteropathogens, $\%$} \\
\hline Cryptosporidium parvum & 27.9 & 22.2 & 0.09 \\
\hline Rotavirus & 17.9 & 16.3 & 0.58 \\
\hline Coronavirus & 6.4 & 8.0 & 0.42 \\
\hline Escherichia coli $\mathrm{F} 5$ & 0 & 0 & 1.00 \\
\hline
\end{tabular}

${ }^{1}$ Calves assigned to the ACD treatment had free access to milk replacer acidified to a target $\mathrm{pH}$ between 4.0 and 4.5 .

${ }^{2}$ Calves assigned to the RES treatment were fed $3 \mathrm{~L}$ of milk replacer twice daily.

${ }^{3}$ Calves were assigned a fecal consistency for $6 \mathrm{wk}$ consecutively.

${ }^{4} \mathrm{Fecal}$ consistency was assessed on a 4 -point scale: $0=$ normal, $1=$ semi-formed and pasty, $2=$ loose consistency, 3 = watery consistency.

${ }^{5}$ Least squares means $(95 \% \mathrm{CI})$ are presented.

${ }^{6} P$-values: treatment $<0.001$, wk $<0.001$, and treatment $\times$ wk $=0.001$.

${ }^{7} \mathrm{~A}$ total of 3 fecal samples were collected from 119 ACD calves and 120 RES calves.

more fluid fecal consistency at wk 5 and 6 , but were similar at all other time points, as compared with the RES calves. The ACD calves tended to have greater odds of fecal shedding C. parvum oocysts compared with RES calves (OR, 95\% CI: 1.4, 1.0 to 1.9). Milk feeding treatment was not associated with rotavirus or coronavirus shedding. Escherichia coli F5 was not detected.

Effects of milk feeding treatment on postweaning disease treatment, mortality, and growth for the replacement heifers are shown in Table 4. Median age for postweaning follow-up did not differ by feeding treatment (ACD: $263 \mathrm{~d}$ and RES: $266 \mathrm{~d}, P=0.71$ ). Similarly, calves on ACD and RES treatments did not differ for postweaning disease treatment (OR, 95\% CI: 1.1, 0.6 to $2.1 ; P=0.80$ ) or mortality (OR, $95 \%$ CI: $0.9,0.3$ to $2.7 ; P=0.80)$. Most heifers requiring treatment were treated for respiratory problems (24 ACD and 23 RES); there were also 3 cases of lameness (2 ACD and 1 RES) and 1 case of systemic infection (1 ACD). Postweaning mortality risks for both treatment groups were low, with postweaning respiratory disease reported as the suspected cause of death for $3 \mathrm{ACD}$ heifers and 5 RES heifers. In addition, 1 ACD heifer died from enteritis, 1 ACD heifer died from systemic infection, 1 ACD heifer died from injury, respectively, and 2 RES heifers died

Table 4. Postweaning disease treatment, mortality, and growth for Holstein replacement heifers assigned to free-access acidified $(\mathrm{ACD})^{1}$ and restricted $(\mathrm{RES})^{2}$ milk replacer feeding treatments

\begin{tabular}{lccc}
\hline Outcome & ACD treatment & RES treatment & $P$-value \\
\hline Number of calves, no. & 113 & 115 & \\
Postweaning disease treatment, $^{3}$ no. $(\%)$ & $25(22.1)$ & $24(20.9)$ & 0.80 \\
${\text { Postweaning mortality, }{ }^{4} \text { no. }(\%)}_{\text {Postweaning growth }^{5}}$ & $6(5.3)$ & $7(6.1)$ & 0.80 \\
ADG for weaning to follow-up, $\mathrm{kg} / \mathrm{d}$ & $0.99(0.96,1.02)$ & $1.00(0.97,1.03)$ & 0.58 \\
BW at follow-up, $\mathrm{kg}$ & $281.2(254.9,307.6)$ & $277.4(251.0,303.8)$ & 0.33 \\
\hline
\end{tabular}

${ }^{1}$ Calves assigned to the ACD treatment had free access to milk replacer acidified to a target $\mathrm{pH}$ between 4.0 and 4.5 .

${ }^{2}$ Calves assigned to the RES treatment were fed $3 \mathrm{~L}$ of milk replacer twice daily.

${ }^{3}$ Treated for at least one disease event between weaning and follow-up.

${ }^{4}$ Died between weaning and follow-up.

${ }^{5}$ Least squares means $(95 \% \mathrm{CI})$ are presented. 
from bloat. No difference was found by milk feeding treatment for ADG after weaning $(P=0.58)$ or $\mathrm{BW}$ at the postweaning follow-up time point $(P=0.33)$.

Effects of milk feeding treatment on postweaning disease treatment, mortality, and growth for veal calves are shown in Table 5. Median age for slaughter measurements did not differ by feeding treatment (ACD: $230 \mathrm{~d}$ and RES: $231 \mathrm{~d}, P=0.85$ ). Veal calves did not differ by milk feeding treatment for the odds of postweaning disease treatment (OR, 95\% CI: 1.5, 0.8 to $2.6 ; P=0.18$ ) or postweaning mortality (OR, $95 \%$ CI: $0.8,0.3$ to $1.7 ; P=0.50)$. Respiratory disease was associated with all cases of postweaning disease in veal calves. Moreover, respiratory disease was the leading cause of postweaning mortality for veal calves (13 ACD, 15 RES), together with 2 calf deaths from bloat (1 ACD, 1 RES); causes of mortality for 3 additional ACD calves were not determined. Milk feeding treatment did not affect length of time required for veal calves to reach slaughter weight $(P=0.85)$. Moreover, no difference was found between the ACD and the RES veal calves for postweaning ADG $(P=0.13)$ or live weight at slaughter $(P=0.66)$. Carcasses from $57 \mathrm{ACD}$ veal calves and 55 RES veal calves were graded at the slaughter facility. Twenty-two carcasses (10 ACD and 12 RES) exceeded the maximum dressed weight restriction for veal and were not eligible to receive a grade classification. Feeding treatment did not affect carcass characteristics $(P=0.62)$. In total, $36 / 47(76.6 \%)$ of the ACD veal carcasses and $31 / 43(72.1 \%)$ of the RES veal carcasses were assigned the Canada A2 grade category, and all of the other carcasses were assessed as Canada A1 grade.

\section{DISCUSSION}

The common goal underlying any milk feeding regimen is to provide calves with sufficient nutrients to support maintenance functions, efficient skeletal and muscle growth, rumen development, and calf health (Davis and Drackley, 1998; Drackley, 2008). Results from this clinical trial demonstrate that free-access feeding of acidified milk replacer supports greater preweaning ADG and structural growth in calves. These findings are consistent with the results of other studies where the effects of enhanced feeding strategies on calf growth were evaluated. Calves reared on enhanced nutrition programs show increased preweaning ADG, lean tissue deposition, efficiency of gain, and stature changes over traditionally fed calves (Diaz et al., 2001; Blome et al., 2003; Terré et al., 2006). Ad libitum milk feeding and large daily milk allowances have also been associated with improved BW gain and structural development (Appleby et al., 2001; Jasper and Weary, 2002; Khan et al., 2007a; Borderas et al., 2009; de Passillé et al., 2011; Hill et al., 2013).

Differences in growth during the milk feeding phase between ACD and RES calves likely resulted from differences in nutrient intake; however, daily milk replacer and solid feed intakes could not be measured in this extensive clinical trial. It has been reported that under similar management conditions, calves fed freeaccess acidified milk replacer consume approximately $10 \mathrm{~L}$ of milk replacer daily and only small quantities of solid feed before weaning (Anderson, 2006, 2008; Todd, 2013). Several other research groups have also documented a negative relationship between enhanced milk feeding and ingestion of solid feedstuffs by calves (Appleby et al., 2001; Jasper and Weary, 2002; Terré et al., 2006; Borderas et al., 2009; Huuskonen et al., 2011).

Although free-access acidified milk replacer feeding promoted greater preweaning growth, ACD and RES calves were expected to exhibit higher ADG than the observed rates of 0.59 and $0.43 \mathrm{~kg} / \mathrm{d}$, as well as greater feeding treatment differences. Calves reared on enhanced feeding strategies, including those fed free-

Table 5. Postweaning disease treatment, mortality, and growth for Holstein veal calves assigned to free-access acidified $(\mathrm{ACD})^{1}$ and restricted $(\mathrm{RES})^{2}$ milk replacer feeding treatments

\begin{tabular}{lcr}
\hline Outcome & ACD treatment & RES treatment \\
\hline Number of calves, no. & 129 & 126 \\
Postweaning disease treatment, ${ }^{3}$ no. $(\%)$ & $47(36.4)$ & $37(29.4)$ \\
Postweaning mortality, ${ }^{4}$ no. $(\%)$ & $13(10.1)$ & $16(12.7)$ \\
Postweaning growth ${ }^{5}$ & $1.33(1.29,1.38)$ & $1.37(1.32,1.41)$ \\
ADG from weaning to slaughter, kg/d & $323.8(315.8,331.9)$ & $324.8(316.6,332.9)$ \\
Live weight at slaughter, kg & & 0.18 \\
${ }^{1}$ Calves assigned to the ACD treatment had free access to milk replacer acidified to a target pH between 4.0 \\
and 4.5.
\end{tabular}


access acidified milk replacer, routinely gain between 0.75 and $1.0 \mathrm{~kg}$ of BW daily (Jasper and Weary, 2002; Blome et al., 2003; Borderas et al., 2009; Miller-Cushon et al., 2013). Moreover, Huuskonen et al. (2011) reported that calves reared on acidified milk at allowances of between 6.0 and $10.0 \mathrm{~L} / \mathrm{d}$ had ADG of 0.61 to $0.78 \mathrm{~g} / \mathrm{d}$. All calves enrolled on this study were fed milk replacer that contained $24 \% \mathrm{CP}$, and thereby should have had greater growth than if a conventional milk replacer (18 to $22 \% \mathrm{CP}$ ) had been fed (Drackley, 2008). The RES calves were provided milk replacer at a higher feeding rate $(6 \mathrm{~L} / \mathrm{d}$, approximately $14 \%$ birth $\mathrm{BW})$ than the traditional restricted rate of 8 to $10 \%$ birth BW, which may partially explain the smaller than expected difference in ADG between the ACD and RES calves. Preweaning $\mathrm{ADG}$ for the $\mathrm{ACD}$ and RES calves may have also been underestimated because weaning weights for the calves were not determined until approximately 1 wk after weaning. As calves make the transition from a milk-based to a fully solid feed diet, they will often experience a growth check in the immediate postweaning period (Sweeney et al., 2010; Khan et al., 2011a). In the current study, this growth check may have been accentuated because a proper step-down weaning protocol was not implemented. Hence, the delay in collecting the weaning measurements may have contributed to the low preweaning ADG.

Calves assigned to the ACD treatment group exhibited greater structural growth than the RES calves. Changes in hip height, hip width, and heart girth from birth to weaning for the RES calves were similar to that of other calves reared on conventional milk replacer feeding regimens (Heinrichs et al., 2003; Lesmeister and Heinrichs, 2004). The ACD calves, however, achieved less preweaning heart girth, body length, and hip height gain than calves reared on step-down milk feeding methods (Khan et al., 2007a, 2011b). One can speculate that the reported differences in structural characteristics for the ACD calves versus step-down milk-fed calves are due to step-down feeding programs being associated with greater overall growth during the preweaning period. Nonetheless, results of the current study demonstrate that the ACD feeding treatment supported increased structural growth over RES. Moreover, it is unlikely that the 1 wk delay in collecting the weaning measurements would have had an effect on these structural characteristics.

Several factors could have influenced growth of ACD and RES calves. Milk feeding treatment was confounded by feed delivery; ACD calves were fed milk replacer by teat, whereas RES calves were fed milk replacer by bucket. Hammell et al. (1988) reported greater BW gains for calves offered ad libitum intake by a teat than by bucket. Furthermore, acidification with formic acid could have affected palatability of the acidified milk replacer. Calves are known to have a preference for sweet tasting substances, such as whole milk or milk replacer (Hellekant et al., 1994; de Passillé and Rushen, 2006). In another study by our research team, acidification to a target $\mathrm{pH}$ between 4.0 and 4.5 resulted in decreased intake by approximately $1 \mathrm{~L} / \mathrm{d}$ under free access feeding conditions, and resulted in more frequent milk meals (Todd, 2013). Moreover, Hill et al. (2013) reported that calves fed milk replacer acidified with citric acid to $\mathrm{pH}$ 4.2 consumed less milk replacer than those offered milk replacer acidified to $\mathrm{pH}$ 5.2. Milk replacer temperature could have also influenced intake and calf growth. Milk replacer for RES calves was mixed fresh at each feeding and was warm when it was offered to these calves. Temperature of the acidified milk replacer was recorded at each weekly visit by the research technicians, and ranged from 13.2 to $27.5^{\circ} \mathrm{C}$, over the study period, due to changes in ambient air conditions. Cold feeding temperatures negatively affect milk replacer intake and subsequent growth performance of calves (Flipot et al., 1972), which together with variability in feeding temperatures, may account for lower than expected ADG for ACD calves. Unmeasured environmental factors, such as elevated ammonia levels and ventilation quality in the preweaned calf housing facilities, could have also negatively influenced performance during the preweaning phase (Heinrichs et al., 2005; Lundborg et al., 2005; Lago et al., 2006).

Replacement heifers and veal calves reared on the ACD feeding regimen were expected to have greater preweaning ADG and subsequently maintain a BW advantage after weaning over the RES animals. No differences in postweaning growth performance were observed. Enhanced milk feeding has been associated with improved preweaning growth and increased postweaning weight gain in some studies (Khan et al., 2007a,b; Miller-Cushon et al., 2013), but not others (Jasper and Weary, 2002; Terré et al., 2006; Hill et al., 2013). Calves that consume ad libitum or large amounts of milk, generally, have lower solid feed intakes (Appleby et al., 2001; Jasper and Weary, 2002; Quigley et al., 2006; Terré et al., 2006; Borderas et al., 2009), as well as delayed rumen development and function, relative to traditionally fed calves (Terré et al., 2006).

Modified weaning practices are recommended to overcome postweaning growth lags. In the current study, calves were weaned over a 5 -d weaning period to encourage solid feed intake, during which ACD calves had access to ad libitum milk for $12 \mathrm{~h} / \mathrm{d}$ and RES calves were fed only once daily. Some evidence shows that calves fed ad libitum milk for $4 \mathrm{~h} / \mathrm{d}$ adjust their feeding behavior and consume milk at rates similar to those when calves have free access throughout the day 
(von Keyserlingk et al., 2006). Thus, one can speculate that ACD calves may have continued to consume large amounts of milk until the final day of weaning, resulting in a relatively abrupt wean off milk, a more difficult transition onto solid feed, poor weight gain during the early postweaning period, and underestimated preweaning ADG because weaning weight was determined approximately $1 \mathrm{wk}$ after weaning was completed. Calves that are abruptly weaned can potentially lose weight during the first week after weaning (Sweeney et al., 2010). Automated feeding technologies can be adopted to facilitate gradual weaning programs. For example, automated milk feeders can be used to gradually reduce milk availability over several days (de Passillé et al., 2011). Sweeney et al. (2010) documented that for calves fed large amounts of milk, gradually reducing milk availability over $10 \mathrm{~d}$, in comparison to abrupt, 4 $\mathrm{d}$, or $22 \mathrm{~d}$ weaning, resulted in the best combination of weaning and postweaning solid feed intakes and growth. It has also been reported that delaying the weaning of calves fed large amounts of milk from 6 to 8 wk of age (Eckert et al., 2015), or possibly out to 10 or 12 wk of age (Meale et al., 2015) is associated with improved nutrient intake, greater growth performance, more gastrointestinal development at weaning, and fewer behavioral signs of weaning distress. Furthermore, de Passillé and Rushen (2016) recently demonstrated performance advantages associated with the implementation of weaning strategies that rely on the calf's ability and willingness to consume starter, especially when calves are fed large amounts of milk. Further research is needed to identify best weaning practices and opportunities to maintain performance benefits of enhanced feeding into postweaning phases of production.

As expected, ACD calves tended to be treated for fewer preweaning disease events than RES calves. However, milk feeding treatment did not affect pre- and postweaning mortality, or postweaning disease treatment. Differences in preweaning disease treatment risk for ACD and RES calves may have resulted from improved nutrition. Khan et al. (2007a) reported that occurrence of diarrhea among enhanced-fed calves was significantly lower than that of calves reared under a restricted feeding regimen. Moreover, in a separate study, calves on a higher plane of nutrition had improved recovery from the effects of disease due to experimentally induced C. parvum infection (Ollivett et al., 2012). Thus, free-access acidified milk replacer feeding may have positively supported preweaned calf health by allowing calves to consume more nutrients from milk. However, differences in detection and treatment of disease events may explain the treatment effect on preweaning disease, potentially reducing internal and external validity of the study results. Farm person- nel were not blind to treatment, and therefore, bias could influence recording of intensity of assessment and selection for disease treatment. Furthermore, meal feeding of RES calves likely facilitated more intense individual observation twice daily and the subsequent detection of changes in appetite and intake. Alternatively, because milk was continuously provided to ACD calves, their feeding behavior may not have been as easily observed. Reported incidence of preweaning disease was considerably lower than estimates used for sample size calculations, which were based on disease treatment information and historic calf health status data collected for this farm. Only $20 \%$ of the calves that died during the preweaning period were treated for disease before death, suggesting disease events may have been under-diagnosed. In addition, the suspected cause of death was not determined for $3 \mathrm{ACD}$ and 2 RES calves. Farm files have been checked to confirm that (1) no records were found of health interventions being administered to those calves listed as dying without receiving prior treatment for disease, and (2) no cause of death was provided by farm staff members for the 3 ACD and 2 RES calves. Hence, without the support of farm records, one can only speculate that for some cases, disease went undetected and the cause of death could not always be established. Moreover, it must be noted that given the large number of hypotheses tested in the current study, there may have been potential for type I error.

Despite the potential under-recording of preweaning disease in this study population, the ACD calves tended to have greater odds of cryptosporidiosis and more fluid fecal consistency. Yet, ACD calves were treated for fewer disease events, and were at no greater risk of death than the RES calves. Taken together, these results support further study into possible associations between free-access acidified milk feeding and recovery from the effects of disease, possibly attributed to having been reared on a higher plane of nutrition (Ollivett et al., 2012).

\section{CONCLUSIONS}

Calves reared on the free-access acidified milk replacer feeding program tended to be treated for fewer preweaning disease events than restricted-fed calves, but no benefits were observed for preweaning mortality, postweaning disease events, or postweaning mortality. Free-access feeding of acidified milk replacer supported greater preweaning ADG and structural growth than traditional restricted milk feeding. These improvements were not maintained during the postweaning period, and no differences in carcass characteristics were observed. 


\section{ACKNOWLEDGMENTS}

Financial support for this study was generously provided by Natural Sciences and Engineering Research Council of Canada (Ottawa, Ontario, Canada), Ontario Ministry of Agriculture, Food and Rural Affairs (Guelph, Ontario, Canada), Dairy Farmers of Ontario (Mississauga, Ontario, Canada), and Ontario Veal Association (Guelph, Ontario, Canada). The authors thank the owners and staff of the dairy farm for their willingness to collaborate on this project, the University of Guelph Dairy Health Management staff for technical support, William Sears (Department of Population Medicine, Guelph, Ontario, Canada) for his advice on statistical analyses, and Bill Lowe (Ontario Veal Association, Guelph, Ontario, Canada) for facilitating the collection of carcass grading information.

\section{REFERENCES}

Anderson, N. 2006. OMAFRA Infosheet: Mimicking Nature's Way for Milk-Fed Dairy Calves-Free-Access Feeding with Acidified Milk.

Anderson, N. 2008. OMAFRA Infosheet: Free-Access Feeding of Acidified Milk-Setting Up the System Using Formic Acid.

Anderson, N. G. 2011. Practical aspects of accelerated feeding of dairy calves. Pages 88-100 in Proc. 44th Annu. Conf. Am. Assoc. Bov. Pract., Sept. 22-24, 2011, St. Louis, MO. American Association of Bovine Practitioners, St. Louis, MO.

Appleby, M. C., D. M. Weary, and B. Chua. 2001. Performance and feeding behaviour of calves on ad libitum milk from artificial teats. Appl. Anim. Behav. Sci. 74:191-201.

Blome, R. M., J. K. Drackley, F. K. McKeith, M. F. Hutjens, and G. C. McCoy. 2003. Growth, nutrient utilization, and body composition of dairy calves fed milk replacers containing different amounts of protein. J. Anim. Sci. 81:1641-1655.

Borderas, T. F., A. M. B. de Passille, and J. Rushen. 2009. Feeding behaviour of calves fed small or large amounts of milk. J. Dairy Sci. 92:2843-2852.

Davis, C. L., and J. K. Drackley. 1998. The Development, Nutrition, and Management of the Young Calf. 1st ed. Iowa State University Press, Ames.

de Passillé, A. M., T. F. Borderas, and J. Rushen. 2011. Weaning age of calves fed a high milk allowance by automated feeders: Effects on feed, water, and energy intake, behavioural signs of hunger, and weight gains. J. Dairy Sci. 94:1401-1408.

de Passillé, A. M., and J. Rushen. 2006. What components of milk stimulate sucking in calves? Appl. Anim. Behav. Sci. 101:243-252.

de Passillé, A. M., and J. Rushen. 2016. Using automated feeders to wean calves fed large amounts of milk according to their ability to eat solid feed. J. Dairy Sci. 99:3578-3583.

De Paula Vieira, A., V. Guesdon, A. M. de Passillé, M. A. G. von Keyserlingk, and D. M. Weary. 2008. Behavioural indicators of hunger in dairy calves. Appl. Anim. Behav. Sci. 109:180-189.

Diaz, M. C., M. E. Van Amburgh, J. M. Smith, J. M. Kelsey, and E. L. Hutten. 2001. Composition of growth of Holstein calves fed milk replacer from birth to 105-kilogram body weight. J. Dairy Sci. 84:830-842.

Dohoo, I., W. Martin, and H. Stryhn. 2009. Veterinary Epidemiologic Research. VER Inc., Charlottetown, Prince Edward Island, Canada.

Drackley, J. K. 2008. Calf nutrition from birth to breeding. Vet. Clin. North Am. Food Anim. Pract. 24:55-86.

Eckert, E., H. E. Brown, K. E. Leslie, T. J. DeVries, and M. A. Steele. 2015. Weaning age affects growth, feed intake, gastrointestinal de- velopment, and behavior in Holstein calves fed an elevated plane of nutrition during the preweaning stage. J. Dairy Sci. 98:6315-6326.

Flipot, P., C. Lalande, and M. H. Fahmy. 1972. Effects of temperature of milk replacer and method of feeding on the performance of Holstein veal calves. Can. J. Anim. Sci. 52:659-664.

Hammell, K. L., J. H. M. Metz, and P. Mekking. 1988. Sucking behaviour of dairy calves fed milk ad libitum by bucket or teat. Appl. Anim. Behav. Sci. 20:275-285.

Heinrichs, A. J., B. S. Heinrichs, O. Harel, G. W. Rogers, and N. T. Place. 2005. A prospective study on calf factors affecting age, body size, and body condition score at first calving of Holstein dairy heifers. J. Dairy Sci. 88:2828-2835.

Heinrichs, A. J., C. M. Jones, and B. S. Heinrichs. 2003. Effects of mannan oligosaccharide or antibiotics in neonatal diets on health and growth of dairy calves. J. Dairy Sci. 86:4064-4069.

Hellekant, G., C. Hård af Segerstad, and T. W. Roberts. 1994. Sweet taste in the calf: III. Behavioral responses to sweeteners. Physiol. Behav. 56:555-562.

Hill, T. M., H. G. Bateman, J. M. Aldrich, J. D. Quigley, and R. L. Schlotterbeck. 2013. Evaluation of ad libitum acidified milk replacer programs for dairy calves. J. Dairy Sci. 96:3153-3162.

Huuskonen, A., M. Huumonen, E. Joki-Tokola, and L. Tuomisto. 2011. Effects of different liquid feeding strategies during the pre-weaning period on the performance and carcass of dairy bull calves. Acta. Agric. Scand. Section A 61:187-195.

Jasper, J., and D. M. Weary. 2002. Effects of ad libitum milk intake on dairy calves. J. Dairy Sci. 85:3054-3058.

Khan, M. A., H. J. Lee, W. S. Lee, H. S. Kim, K. S. Ki, T. Y. Hur, G. H. Suh, S. J. Kang, and Y. J. Choi. 2007a. Structural growth, rumen development, and metabolic and immune responses of Holstein male calves fed milk through step-down and conventional methods. J. Dairy Sci. 90:3376-3387.

Khan, M. A., H. J. Lee, W. S. Lee, H. S. Kim, S. B. Kim, K. S. Ki, J. K. Ha, H. G. Lee, and Y. J. Choi. 2007b. Pre- and postweaning performance of Holstein female calves fed milk through step-down and conventional methods. J. Dairy Sci. 90:876-885.

Khan, M. A., D. M. Weary, and M. A. G. von Keyserlingk. 2011a. Invited review: Effects of milk ration on solid feed intake, weaning, and performance in dairy heifers. J. Dairy Sci. 94:1071-1081.

Khan, M. A., D. M. Weary, and M. A. G. von Keyserlingk. 2011b. Hay intake improves performance and rumen development of calves fed higher quantities of milk. J. Dairy Sci. 94:3547-3553.

Lago, A., S. M. Mc, T. B. Guirk, N. B. Bennett, K. Cook, and V. Nordlund. 2006. Calf respiratory disease and pen microenvironments in naturally ventilated calf barns in winter. J. Dairy Sci. 89:4014-4025.

Lesmeister, K. E., and A. J. Heinrichs. 2004. Effects of corn processing on growth characteristics, rumen development, and rumen parameters in neonatal dairy calves. J. Dairy Sci. 87:3439-3450.

Lundborg, G. K., E. C. Svensson, and P. A. Oltenacu. 2005. Herd-level risk factors for infectious diseases in Swedish dairy calves aged 0-90 days. Prev. Vet. Med. 68:123-143.

McGuirk, S. M. 2008. Disease management of dairy calves and heifers. Vet. Clin. North Am. Food Anim. Pract. 24:139-153.

Meale, S. J., L. N. Leal, J. Martin-Tereso, and M. A. Steele. 2015. Delayed weaning of Holstein bull calves fed an elevated plane of nutrition impacts feed intake, growth and potential markers of gastrointestinal development. Anim. Feed Sci. Technol. 209:268-273.

Miller-Cushon, E. K., R. Bergeron, K. E. Leslie, and T. J. DeVries. 2013. Effect of milk feeding level on development of feeding behavior in dairy calves. J. Dairy Sci. 96:551-564.

NAHMS (National Animal Health Monitoring System). 2016. Dairy 2014: Dairy Cattle Management Practices in the United States, 2014. Accessed Jul. 28, 2016. https://www.aphis.usda.gov/animal_ health/nahms/dairy/downloads/dairy14/Dairy14_dr_PartI.pdf.

Nocek, J. E., and D. G. Braund. 1986. Performance, health, and postweaning growth on calves fed cold, acidified milk replacer ad libitum. J. Dairy Sci. 69:1871-1883.

Ollivett, T. L., D. V. Nydam, T. C. Linden, D. D. Bowman, and M. E. Van Amburgh. 2012. Effect of nutritional plane on health 
and performance in dairy calves after experimental infection with Cryptosporidium parvum. J. Am. Vet. Med. Assoc. 241:1514-1520.

Quigley, J. D., T. A. Wolfe, and T. H. Elsasser. 2006. Effects of additional milk replacer feeding on calf health, growth, and selected blood metabolites in calves. J. Dairy Sci. 89:207-216.

Soberon, F., E. Raffrenato, R. W. Everett, and M. E. Van Amburgh. 2012. Preweaning milk replacer intake and effects on long-term productivity of dairy calves. J. Dairy Sci. 95:783-793.

Soberon, F., and M. E. Van Amburgh. 2013. LACTATION BIOLOGY SYMPOSIUM: The effect of nutrient intake from milk or milk replacer of preweaned dairy calves on lactation milk yield as adults: A meta-analysis of current data. J. Anim. Sci. 91:706-712.

Stobo, I. J. F. 1983. Milk replacers for calves. Pages 113-140 in Recent Advances in Animal Nutrition. W. Haresign, ed. Butterworths, London, UK.

Sweeney, B. C., J. Rushen, D. M. Weary, and A. M. de Passillé. 2010. Duration of weaning, starter intake, and weight gain of dairy calves fed large amounts of milk. J. Dairy Sci. 93:148-152.
Terré, M., M. Devanta, and A. Bach. 2006. Performance and nitrogen metabolism of calves fed conventionally or following an enhanced growth feeding program during the preweaning period. Livest. Sci. 105:109-119.

Todd, C. G. 2013. An investigation into the effects of free-access acidified milk replacer feeding programs on the productivity and welfare of the calf. PhD Diss. University of Guelph, Guelph, Ontario, Canada.

Trotz-Williams, L. A., S. W. Martin, D. Martin, T. Duffield, K. E. Leslie, D. V. Nydam, F. Jamieson, and A. S. Peregrine. 2005. Multiattribute evaluation of two simple tests for the detection of Cryptosporidium parvum in calf faeces. Vet. Parasitol. 134:15-23.

von Keyserlingk, M. A. G., F. Wolf, M. Hotzel, and D. M. Weary. 2006. Effects of continuous versus periodic milk availability on behaviour and performance of dairy calves. J. Dairy Sci. 89:2126-2131.

Woodford, S. T., H. D. Whetstone, M. R. Murphy, and C. L. Davis 1987. Abomasal pH, nutrient digestibility, and growth of Holstein bull calves fed acidified milk replacer. J. Dairy Sci. 70:888-891. 